\title{
Evaluation of the Effect of Knowledge Management Process on Human Resource Productivity
}

\author{
Mohammad Naderi Moghaddam ${ }^{1}$, Sajjad Habibian², Farhad Hadinejad ${ }^{3, *}$ \\ ${ }^{1}$ Department of Management, Islamic Azad University, Naraq Branch, Iran \\ ${ }^{2}$ Department of Management, Shahed University, Tehran, Iran \\ ${ }^{3}$ Department of Industrial Management, Allameh Tabataba'i University, Tehran, Iran \\ Email address: \\ Farhad_hdng@yahoo.com (F. Hadinejad) \\ *Corresponding author
}

\section{To cite this article:}

Mohammad Naderi Moghaddam, Sajjad Habibian, Farhad Hadinejad, Evaluation of the Effect of Knowledge Management Process on Human Resource Productivity. Engineering and Applied Sciences. Vol. 2, No. 4, 2017, pp. 59-65. doi: 10.11648/j.eas.20170204.11

Received: May 28, 2017; Accepted: June 19, 2017; Published: July 20, 2017

\begin{abstract}
The main purpose of this research is to examine the impact of knowledge management processes on human resource productivity. Knowledge management processes included knowledge acquisition, creation, storage, distribution and application, in addition the human resource productivity included twofold of productivity such as; effectiveness and efficiency. This research is a correlate on al research and is concerns about finding relationship between variables. The population includes all the employees in Tehran channel of the Islamic Republic of Iran Broadcasting and 185 subjects were selected as sample using Cochran sampling method. Data were collected by two questionnaires. To testing the hypotheses, correlation test and regression analysis were used. The results showed that the distribution and application of knowledge plays important role in the productivity of human resources. The stages of knowledge acquisition, creation and storage of knowledge have little to do with performance. This result is reasonable, because acquisition, creation and storage of knowledge are the previous stages for involving people in the organization but the role of people has become more tangible and has a positive influence on human resource productivity. The variance was calculated for each component of the study using ANOVA between groups and within groups. The test results indicate that all components of research in different educational levels did not differ.
\end{abstract}

Keywords: Knowledge Management Processes, Knowledge Acquisition, Knowledge Distribution, Human Resource Productivity

\section{Introduction}

Today, knowledge is one of the fundamental driving forces for the success of the business. Organizations have become more knowledge-oriented and spend for "man power" instead of "minds". The need for knowledge promoting is increasing, thus the successful organizations know the staffs as the source of income and quality. For them, the concepts of "we and they" are not raised. Their philosophy is to trust employees, respect for employees, putting them in winners' line, allowing them to express themselves and dealing maturely, and given the training and development. The investment of top organizations in human capital especially in recruiting, training and development programs for their professional skills is very significant. These organizations use the full potential of their employees at all levels, from the individual, team and organization. These organizations create a learning organization through investment for training, improving the quality improvement skills and problemsolving skills, management development programs and identifying and acquiring new capabilities [1]. In many recent studies in the field of strategic management, the role of knowledge management in organizations has been emphasized as a basis for competitive advantage [2, 3].

Knowledge management is the process by which organizations produce, get, capture and using of knowledge for improving organizational productivity [4]. It should be noted that organizations cannot work in the knowledgecreation, but also the interaction of the knowledge-creation is going to happen. On the other hand, tacit knowledge exists in 
the public mind as two forms of mental models and technical skills, if it is not converted into explicit knowledge and is not shared in the organization, it will be of little value. Organizations can affect their behavior and achieve superior performance by accessing, sharing and using explicit and implicit knowledge [5].

Skyrme (2003) states that knowledge management is a systematic and explicit system of knowledge which is tied into the processes of creating, gathering, dissemination and application of knowledge that is used in converting individual knowledge into collective knowledge and two points are important in the application of knowledge: Knowledge sharing and innovation [6].

Knowledge management is effective is improving quality, increasing efficiency, having updated information, increasing efficiency, customer satisfaction, improving decision making and perceiving organizational support [7]. Organizational knowledge management has changed customs and daily operations, like the changes made by thinking on education and culture. By designing and organizing the knowledge management process, tacit knowledge, skills and attitudes can be transferred into procedures, standardization, and analysis of documentation content and a field can be provided for competitive advantage and sustainable development [8]. Strategic approach is essential to achieve competitive advantage and improve performance. Previous research suggests that knowledge management improves the organizational performance [9]. According to the above, the main purpose of this study is to examine the effect of knowledge management on human resource productivity in Tehran channel of the Islamic Republic of Iran Broadcasting.

\section{Knowledge Management Process}

Knowledge management is a term that has been widely used in recent years in many organizations and has become a critical issue in the field of business. Today most of the scientific communities argue that only organizations can retain the long-term competitive advantages that have superior knowledge power and produce a new knowledge in addition to the proper use and optimization of their existing knowledge. Today's managers have a duty to fulfill the organization's mission and goals and also maintain the organizational values which is not possible without the production of knowledge and its proper management. Knowledge management refers to a set of processes in which a continuous flow of knowledge in a society increasingly is driven [10]. This paper considers knowledge management as the process of knowledge creation, validation, presentation, dissemination and application. These five areas of knowledge management in organizations provide the field of education, feedback, training, retraining or removal that is needed usually for the creation, organization, preservation and restoration capabilities. Many information professionals store and retrieve data for its systematic reuse but in a knowledgebased organization, these are not enough and the information must be in accordance with the real needs of the business, in terms of quality control and business processes. Through the interrelation between mental processes and business information the new knowledge and understanding are created (Figure 1).

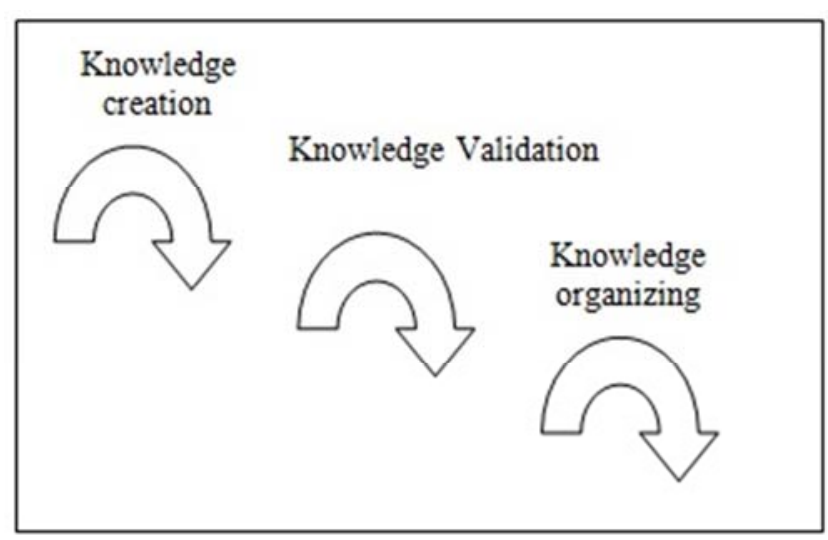

Figure 1. The processes of knowledge transfer.

Criteria for evaluating the usefulness of knowledge are often unclear. However, if an organization considers knowledge useful in its current tasks and activities, it must ensure that working groups would be able to quantify and assess their knowledge [11]. Using of patterns of interaction among members, technologies, and culture of an organization can be faced with difficult circumstances and this is why some experts have called this interactive model as a collection of organization minds. We continue to evaluate the proposed definitions in relation to these processes.

\subsection{Knowledge Creation}

Knowledge creation refers to the ability of creating new and useful ideas and solutions [12]. Organizations create new realities and concepts with the development and restructuring of prior knowledge and different methods. Knowledge creation is an important process in which motivation; belief, experience, and luck play an important role [13]. The criterion of measuring new knowledge is its role in resolving current issues and innovations in the market.

\subsection{Knowledge Validation}

Knowledge validation refers to the extent that firms can affect the knowledge and assess its influence on the organizational environment, because a part of last knowledge needs revising and adapting to the current realities. The multifaceted interaction between technologies, techniques and knowledge is needed to assess reliability [14]. For example, when an organization uses a new set of technologies, tools, processes and procedures it needs the improvement of its employees' skills in order to adapt itself to the new competitive realities. Validating knowledge is the strict process of controlling, testing and continuously improving the knowledge base for existing and potential reality. In general, the progress in a field creates new information, theories, laws and regulations and some old outdated rules are removed. Thus, reviewing, testing and 
continuously increasing the credibility of the knowledge base necessary are needed for organizations to meet current knowledge.

\subsection{Knowledge Giving}

Knowledge giving suggests ways in which knowledge is giving to the organizational members. In general, organizations can adopt different trends to build their knowledge base. However, organizational knowledge is presented at different positions and involves different processes. Members of communities are involving with a set of procedures. If it is necessary to learn the specific work practices, delaying in integration of new knowledge is natural and necessary. Thus, an organization can establish the same standards and use similar patterns to represent "data", "information" and "knowledge".

\subsection{Knowledge Distribution}

It is essential to share knowledge prior the using in organizational levels within the organization. The interaction between technologies, techniques and people can have a direct effect on the distribution of knowledge. In traditional organizational structures, depending on the form of control and pre-defined roles, opportunities, distribution of knowledge and the interaction between technologies, techniques and people will decrease. But in new structures (horizontal), strengthening and policy openness accelerate the knowledge flow among departments and individuals.

\subsection{Knowledge Using}

In general, organizational knowledge must be used in products, services and organizational processes. If an organization cannot easily determine the correct form of knowledge in the right place it will face with difficult in the competitive arena. When the innovation and creativity are the victory paths in today's world, organizations must have the right knowledge at the right place henceforth. The criterion for evaluating the usefulness of knowledge is often unclear. However, if an organization considers knowledge as useful in its current tasks and activities, it should ensure that working groups would be able to quantify and assess their knowledge. Organizations should create an environment for sharing and transferring knowledge among members to conduct individual knowledge to organizational goals [15], and teach the individuals with the concepts of their interactions. To develop "Collection knowledge", they should guide every activity in order to develop and interact the functions.

In brief, knowledge management refers to the corporate culture change in business processes, in order to make possible the sharing of information. This is similar to activities in cultural and social sub-sets. In dynamic environments, organizations are facing a series of problems, and unwanted and unforeseen situations which are difficult to control by any individual in the organization. Complex tasks are not done by one person in an organization, but the interaction between technologies, techniques, and people will assist an organization in carrying out its critical functions. So one of the difficult tasks of managing is creating cooperation through exchange and sharing of knowledge between different packages of information.

\section{The Role of Knowledge Management in Human Resource Productivity}

Knowledge-based management school has a considerable empirical support. Studies show the direct influence of employee knowledge on competitive advantage [16]. The profitability and value added of each employee [17]. In the knowledge-based view, sustainable competitive advantage is given to organizations only through knowledge, because the amount of knowledge in outside organizations is far more than knowledge in inside and organizations are capable of learning more and more to take steps to achieve sustainable competitive advantage [18, 19]. In resourcebased view, organization's assets must be valuable, unique and irreplaceable, and the institutional knowledge has a role in gaining competitive advantage more than any other factor [3]. Among the different types of knowledge, the most appropriate source of corporate competitiveness, knowledge and technical staff who know. In this study, the importance of other types of knowledge is classified as follows:

Technical knowledge, capabilities, people, knowledge products, knowledge about markets and knowledge about competitors. This study also discusses the positive implications of knowledge:

Around $83 \%$ of companies believe that the direct results of the top, rather than reacting to environmental challenges, innovate, improve decision-making and greater efficiency. Around $82 \%$ of companies believe that the direct benefit of proper knowledge, more flexible company [20].

There is no doubt that knowledge management in a larger size causes individual and organizational learning aspects of the each of these aspects can play an important role in organizational productivity. Mac LC on (2000) at the individual and organizational learning is considered. Although such key factors that ultimately leads to the individual learning and organizational learning, organizational productivity and human resource productivity, the But in the process of doing daily activities of an institution, employees encounter questions such as the following questions:

What knowledge do people need to do their jobs?

And what can help them achieve it?

Senge's first wave of knowledge management knowledge, but also about information, how to capture it, store it, retrieve it and access it. The first wave of knowledge management, organizational knowledge, we face today is the second generation, "MD The second generation organizational knowledge discovery, and it deserves respect as an important concept and agreed. Understand how knowledge is created, shared and how it is disseminated within the organization. 
The provisions of the second generation of theory and knowledge of the processes associated with the life cycle of human knowledge, while thinking of the first generation of such a foundation-no [21]. One of the most fundamental questions in the field of human resource strategy that arises is director of the Institute for how any organization's human resource management cancan be more efficient? This is due to the fact that competitive advantage is achieved in productivity [22]. What is the basis of productivity, an educated man of great knowledge and wisdom that can be thought of goods, products and services are changed? In a study, "The influence of human resource management capabilities through knowledge management in innovation variable" is examined. The results showed that human resource management capabilities are positively related to knowledge management in innovation. In addition, human resource management functionality directly and indirectly through the mediation of knowledge management has a positive influence on innovation [23].

In organizations, there are many employees in the event that capabilities, thinking, mentality and ability of employees to optimal performance becomes. The vibrant, profitable and would be superior. Excellence organizations depend on employees, i.e. to have excellent organizational excellence and superior regarding the need to do so with the excellence of the staff, the organization began and continued excellence. Excellence and Excellence staff, training of mental abilities, thoughts, attitudes and knowledge obtained. Accordingly, organizations need to work in a systematic human resource development, and application to follow. One of these techniques, implementation and application of the principles of knowledge management in organizations The people who developed this way so that they can grow and thrive sustainable benefits for the organization because the process is critical to the efficiency, productivity, and foster employees who want to build new capacity.

Once they have the necessary development, institutionalization and improved productivity. In the process of developing human resources staff to be equipped with a set of quality that the quality cause acting is Holistic and balanced. One of the indicators of human development, efficient operation, and this means that it is not the development of professional practice, this is but one of its expertise in the form of productivity in the organization of knowledge and concepts related strategies as components are essential for the organization to survive and remain competitive accumulate. According to management, knowledge management is necessary. For both the public and private sectors, knowledge management as a prerequisite to productivity and is more flexible. Technology-driven organizations have found that competitive advantages are transient and only sustainable competitive advantage that they are employees This can cause learning curve having been elected, for organizations to adapt quickly to respond faster, shaping our industry are forward looking effort are [24].

\section{Research Methodology}

The present study is applied in terms of purpose, descriptive-survey in terms of data collection method and correlational in terms of relationships between variables. The population includes all the employees in Tehran channel of the Islamic Republic of Iran Broadcasting and 357 subjects were selected as sample using Cochran sampling method. Data were collected by questionnaire. Data were collected by questionnaire. In this study, two standardized questionnaires were used in the process of knowledge management and workforce productivity. Cronbach's coefficient alpha was used to test reliability.

Research hypotheses are:

(1) $\mathrm{KM}$ process has a significant positive influence on human resource productivity (HRP).

a) Knowledge acquisition has a significant positive influence on HRP.

b) Knowledge creation has a significant positive influence on HRP.

c) Knowledge storage has a significant positive influence on HRP.

d) Knowledge distribution has a significant positive influence on HRP.

e) Knowledge using has a significant positive influence on HRP.

(2) $\mathrm{KM}$ process has a significant positive influence on the efficiency.

(3) $\mathrm{KM}$ process has a significant positive influence on the effectiveness.

(4) The average knowledge management processes do not have any significant difference in education levels.

(5) The average human resource productivity does not have any significant difference in education levels.

In order to display the status of demographic variables and explain the components of demographic variables on the mean, standard deviation, frequency, maximum, and minimum data has been used. In addition, the questions asked in the questionnaire based on a five-point Likert scale (strongly disagree... strongly agree) have been set. It has been tried to use the statistical properties of the sample analyzed and presented in tables and graphs. The population in the present study we test the normality of Kolmogorov Smirnov will be used, In addition, inferential statistics for hypothesis testing, such as correlation test for determine the type and extent of the relationship between variables, regression analysis to investigate the effect of independent variables on the dependent variables will be used.

\section{Results}

Descriptive statistics for the demographic variables included gender, age, educational level and distribution of components was used. According to the analysis of the data, 43 percent of the population in the frequency range 31 to 40 years and $37 \%$ were in the age range 41 to 50 years of age, 
indicating the age of the employee. In addition, 20 percent of the population in the age range 20 to 30 years old. The most frequent men with ample staff of 96 people. 72 females and 12 did not specify their gender. In terms of education, 40 percent of the employee population has a degree, diploma, 23 percent, 20 percent and 17 percent holds a MS degree or higher. According to Table 1, all the values of Cronbach's alpha for factor larger than 0.7 , therefore, calculated the Cronbach's alpha for the questionnaire show that the reliability of the instrument.

Table 1. Mean, standard deviation and Cronbach's alpha components.

\begin{tabular}{llll}
\hline Cronbach's alpha & SD & Average & Component \\
\hline 0.888 & 0.6 & 2.3 & Knowledge Acquisition \\
0.877 & 0.9 & 2.33 & Knowledge Creation \\
0.881 & 0.49 & 2.85 & Knowledge storage \\
0.862 & 0.65 & 2.37 & Knowledge Distribution \\
0.875 & 0.65 & 2.88 & Knowledge Using \\
0.861 & 0.52 & 2.55 & KM Process \\
0.886 & 0.77 & 2.77 & Efficiency \\
0.876 & 0.73 & 2.55 & Effectiveness \\
0.87 & 0.66 & 2.66 & HR Productivity \\
\hline
\end{tabular}

Among the variables, the use of components with a mean of 2.88 has the highest mean and the acquisition of knowledge with the lowest average of 02.30 out of it. KM process an average of 2.55 and 2.66 is an average productivity of human resources. Among the components of research, knowledge creation has the highest standard deviation (0.90) and storage of knowledge has the lowest standard deviation (0.49).

\subsection{Hypotheses Test Results}

To investigate the normal distribution of the dependent variable and the Kolmogorov-Smirnov test was used. The test results showed that with respect to the $(Z=0827)$ and significant level $(\mathrm{P}$ Value $=.501)$ variable using of human resources is the normal distribution. Regression analysis was used to test the hypothesis. An independent review of the assumptions considered in the regression residuals from each other. To check the remaining independent from each other, Watson used the camera test. As Table 2 indicates that the value of the DW statistic range of 1.5 to 2.5 is. In the first hypothesis there is no correlation between the residuals of the regression cannot be rejected. Results of regression analyzes are shown in Table 2.

Table 2. Results of regression analysis, and the camera-Watson test.

\begin{tabular}{llllll}
\hline Sig. & Durbin-Watson & F & $\begin{array}{l}\text { Standard } \\
\text { error }\end{array}$ & $\begin{array}{l}\text { The coefficient of } \\
\text { determination }\end{array}$ & Hypothesis \\
\hline 0.011 & 1.796 & 7.41 & 0.602 & 0.209 & (1) Influence of KM process on HR productivity \\
0.153 & 1.918 & 2.16 & 0.653 & 0.072 & (a) Influence of knowledge acquisition on HR productivity \\
0.099 & 1.646 & 2.919 & 0.645 & 0.094 & (b) Influence of knowledge creation on HR productivity \\
0.169 & 1.806 & 1.997 & 0.655 & 0.067 & (c) Influence of knowledge storage on HR productivity \\
0.003 & 1.662 & 1.968 & 0.574 & 0.281 & (d) Influence of knowledge distribution on HR productivity \\
0.018 & 1.549 & 6.363 & 0.612 & 0.185 & (e) Influence of knowledge using on HR productivity \\
0.059 & 1.719 & 3.879 & 0.738 & 0.122 & (2) Influence of KM processes on efficiency \\
0.009 & 1.668 & 7.802 & 0.654 & 0.218 & (3) Influence of KM processes on effectiveness \\
\hline
\end{tabular}

Influence of $\mathrm{KM}$ process on human resource productivity at the level of $95 \%$ was confirmed. The extent of the influence is determined according to the value of the coefficient indicates a positive direct effect. Therefore, KM process of predicted HR productivity is 0.209. Thus, Hypothesis (1) was confirmed by research. Evaluation of (a) showed that knowledge acquisition with hypothesis testing regard to the amount of $\operatorname{sig}=0.153$ no significant influence on HR productivity, thus rejecting the hypothesis of a (a) result. Indicates (b) hypothesis was that the DW statistic 1.646 is the assumed correlation between errors is rejected and can be used in the regression. The coefficient of determination indicates positive results to predict the HR productivity. But given the level of error greater than $5 \%$ of the coefficients are not significant and therefore reject the hypothesis of a (b) result.

Evaluation of linear regression indicates that sig $=0.169$ sets, hence the error levels above 5 percent, resulting in significant regression coefficients into the above hypothesis is not rejectc) ed). Therefore, influence of knowledge storage on HR productivity is not significant. Survey of (d) hypothesis indicated that DW statistic 1.662 is the assumption that there is no correlation between the residual of the regression can be used and is not rejected. The coefficient of determination represents HR productivity is a positive predictor. The predictive value of the test with respect to $\mathrm{F}$ (10.968) represents knowledge distribution of the predictability is high. confidence level is $95 \%$, thus confirming the hypothesis (d). Survey of (e) hypothesis was that there is no correlation between the residuals and the significance level is less than 5\% error rate. Investigation into the regression for Hypothesis (2) suggests that error level is greater than 5 percent as a result of hypothesis (2) is rejected and $\mathrm{KM}$ processes have a significant influence on efficiency. Third hypothesis suggests that there is no correlation between the residuals and the significance level is less than 5\% error rate. The coefficient of determination indicates that KM processes to predict the effectiveness of 0.218 , thus Hypothesis (3) is confirmed. The predictive value with respect to the $\mathrm{F}$ value is vital. ANOVA test to test the hypothesis that the mean level of education was not their data is used. Test results are summarized in Table 3. 
Table 3. Results of ANOVA.

\begin{tabular}{|c|c|c|c|c|c|}
\hline Test results & Sig & Statistics F & Variance & The sum of squares & Hypothesis \\
\hline Hypothesis is confirmed & 0.256 & 1.433 & $\begin{array}{l}1.444 \\
8.732\end{array}$ & Between the groups. Within groups & $\begin{array}{l}\text { knowledge acquisition mean does not } \\
\text { difference in education levels }\end{array}$ \\
\hline Hypothesis is confirmed & 0.45 & 0.909 & $\begin{array}{l}2.238 \\
21.345\end{array}$ & Between the groups. Within groups & $\begin{array}{l}\text { knowledge creation mean does not } \\
\text { difference in education levels }\end{array}$ \\
\hline Hypothesis is confirmed & 0.141 & 1.938 & $\begin{array}{l}1.304 \\
5.7\end{array}$ & Between the groups. Within groups & $\begin{array}{l}\text { knowledge storage mean does not } \\
\text { difference in education levels }\end{array}$ \\
\hline Hypothesis is confirmed & 0.108 & 2.231 & $\begin{array}{l}0.512 \\
9.761\end{array}$ & Between the groups. Within groups & $\begin{array}{l}\text { knowledge distribution mean does not } \\
\text { difference in education levels }\end{array}$ \\
\hline Hypothesis is confirmed & 0.484 & 0.842 & $\begin{array}{l}1.097 \\
11.296\end{array}$ & Between the groups. Within groups & $\begin{array}{l}\text { knowledge application mean does not } \\
\text { difference in education levels }\end{array}$ \\
\hline Hypothesis is confirmed & 0.275 & 1.365 & $\begin{array}{l}2.365 \\
15.014\end{array}$ & Between the groups. Within groups & $\begin{array}{l}\text { Efficiency mean does not difference in } \\
\text { education levels }\end{array}$ \\
\hline Hypothesis is confirmed & 0.446 & 0.919 & $\begin{array}{l}1.47 \\
13.87\end{array}$ & Between the groups. Within groups & $\begin{array}{l}\text { Effectiveness mean does not difference in } \\
\text { education levels }\end{array}$ \\
\hline Hypothesis is confirmed & 0.252 & 1.447 & $\begin{array}{l}1.121 \\
6.714\end{array}$ & Between the groups. Within groups & $\begin{array}{l}\text { KM processes mean does not difference in } \\
\text { education levels }\end{array}$ \\
\hline Hypothesis is confirmed & 0.366 & 1.102 & $\begin{array}{l}1.452 \\
11.421\end{array}$ & Between the groups. Within groups & $\begin{array}{l}\text { HR productivity mean does not difference } \\
\text { in education levels }\end{array}$ \\
\hline
\end{tabular}

For each component of the study, the amount of variance between groups and the variance within groups-were calculated. F statistics indicate the proportion of variance between groups to the variance within groups is the amount due to the significance level is greater than 0.05 , Research indicates that all components of differing educational levels did not differ. The results confirm the hypotheses (4) and (5).

\section{Discussion and Conclusion}

The main purpose of this research is to examine the influence of KM process on HR productivity in Tehran channel of the Islamic Republic of Iran Broadcasting. KM processes as independent variables includes of knowledge acquisition, knowledge creation, knowledge storage, knowledge distribution and knowledge using, HR productivity as the dependent variable includes of effectiveness and efficiency were examined. The results showed that the distribution and using of knowledge plays important role in HR productivity. The processes of knowledge acquisition, creation and storage of knowledge have little to do with performance. This result is reasonable, because the three phases of the acquisition, creation and storage must be involved before involving the individuals' role in the organization, but in the people involved in the distribution and application of knowledge more tangible, and have a positive influence on human resource productivity. This result is reasonable, because the three phases of the acquisition, creation and storage before a more involved role in the organization, But the distribution and using of knowledge, the role of more tangible, and have a positive influence on human resource productivity. The results of the research accordance to Rajaeipor and Rahim (2008), Zahedi and Najari (2008) researches [25, 26].

Human resources in achieving goals of $\mathrm{Km}$ management can help a lot to do, because knowledge is shared between individuals. Ensure that the organization has the needed intellectual capital, knowledge management is an important issue in and to do this we find that the role. Measures such as expansion teams and work groups, networks and communities, business, design jobs and career management practices are knowledge workers in this category. In many organizations, employee's conversations with each other in a useless and without value added activity is seen. If this communication can provide a suitable ground for the development of knowledge sharing and HR management can play an active role in this field.

Knowledge to recruit outstanding people and helping them learn and grow personally and professionally with them. And to encourage people to participate in professional networks, and operating relationship that transcends organizational boundaries extend. Knowledge creation through human resource management for individuals, groups and teams by creating a supportive environment create organizational problems and innovative solutions to the challenges [27]. Implement knowledge management processes, the acquisition, creation, storage, distribution and using of knowledge in organizational development play a vital role In addition, organizational learning main strategy for human resources and organizational knowledge work productivity is improved. Therefore, organizations will be able to operate successfully in the processes of knowledge management. Efficiency, human resource management will be this motion requires a simple application of knowledge within organizational units the influence of methods and processes, reduce costs and increase productivity is redundant. As a learning organization, need to develop the cases tend to learn and develop mechanisms to support and enable the learning of individuals.

\section{References}

[1] Isakhani, A. (2008), organization with superior performance, Tadbir magazine, Vol. 19, No. 192.

[2] Argote, L. \& Ingram, P. (2000). Knowledge transfer: a basis for competitive advantage in firms, Organizational Behavior and Human Decision Processes 82 (1), 150-169. 
[3] Barney, J. B. (2001), Is the resource-based view a useful perspective for strategic management research? Yes, Academy of Management Review, 26, 41-56.

[4] Barney, J. B. (1991), Firm resources and sustained competitive advantage. Journal of Management, 17, 100-120.

[5] Chang, M. Y., Hung, Y. C., Yen, D. C. ND Tseng, P. T., 2009, "The research on the critical success factorsof knowledge management and classification framework project in the Executive Yuan of Taiwan Government", Expert Systems with Applications, 9(12), pp. 5376-5386.

[6] Motwani, J., Gopalakrishna, P \& Subramanian, R., 2003. Source of knowledge acquisition by U. S managers: An empirical analysis. Idea group publishing.

[7] Skyrme, D. (2003). "Knowledge management making sense of anoxymoron". http:// Skyrme. Com.

[8] Wang, E., Klein, G., \& Jiang, J. J. (2007). "IT support in manufacturing firms for a knowledge management dynamic capability link to performance". International Journal of Production Research, Vol .45, No. 11, PP: 2419-2434.

[9] Chen, C., 2004, "The effects of knowledge attribute, alliance characteristics, and absorptive capacity on knowledge transfer performance", R\&D Management, 3(9), pp. 311-321.

[10] Holsapple CW, Jones K.(2005) Exploring secondary activities of the knowledge chain. Knowledge and Process Management; 12(1): 3-31.

[11] Santosus, M. \& Surmacz, J.(2004), The ABCS of knowledge management, Knowledge Management Research Center, http://www.cio.com/research/ Knowledge based assets.

[12] Collis, D. J. \& Montgomery, C. A. (1995), Competing or resources: strategy in the 1990s, Harvard Business Review, Vol.73, No. 4, pp. 118-28.

[13] Marakas, G. M. (1999), Decision Support Systems in the Twenty-first Century, prentice-Hall, Englewood Cliffs, NJ.

[14] Lynn, G. S. Morone, J. G. \& Paulson, A. S. (1996). Marketing and discontinuous innovation: the probe and learn process, California Management Review, Vol. 38, pp.8-37.

[15] Bhatt, G. (2000), Organizing Knowledge in the Knowledge development cycle, Journal of Knowledge Management, Journal of Business Transformation, Vol. 4, No. 1, pp. 15-26.
[16] Nonaka, I. \& Takeuchi, H. (1995). The Knowledge-Creating Company: How Japanese Companies Create the Dynamics of Innovation. New York, NY: Oxford University Press.

[17] Makovec-Brencic, M., \& Zabkar, V. (2001). Competitive Advantage as a Result of Non-price Factors: Application of the Structural Equation Model, Economic and Business Review, Ljubljana, Vol. 3, No. 1, pp. 25-4.

[18] Cater, T., \& Alfirevic, N. (2003). Sources of Competitive Success of Large Enterprises in Transition: The case of Croatia and Slovenia. In: Enterprise in Transition: 5th International Conference, Tučepi, 22-24 May 2003, Faculty of economics, Split, pp. 2372-2392.

[19] Amiri, M \& Hadinejad, F (2016). Assessment and analysis of indicators of productivity in manufacturing industries with using PROMETHEE technique, Quarterly journal of Productivity Management, Vol. 9,No 35, pp. 7-38.

[20] Zack, M. H. (1999). Developing a knowledge strategy, California Management Review, 41(3).

[21] Riesenberger, J. R. (1998), Knowledge-The Source of Sustainable Competitive Advantage. Journal of International Marketing, East Lansing, Vol. 6, No. 3.

[22] McElroy, M. W.(2000), "Integrating complexity theory, knowledge management and organizational learning", Journal of Knowledge Management, Vol. 4, Iss: 3, pp. $195-203$.

[23] Martenson, M. (2000), Evaluation of knowledge management point as a management tool, translation: M. Majdam, Tadbir Magazine, No. 110.

[24] Ozbag, G. K., Esen, M., \&Esen, D. (2013). The Influence of HRM Capabilities on Innovation Mediated by Knowledge Management Capability. Procedia - Social and Behavioral Sciences, 99, 784-793. doi:10.1016/j.sbspro.2013.10.550.

[25] Rajaeipour, S. \& Rahimi, H. (2008), Survey of relationship between knowledge management transformation process and performance of faculty members, Humanities and Social Sciences, 8 (4 (Special Management 31)): 59-76.[In persian].

[26] Zahedi, Sh. \& Najjari, R. (2008), The productivity of human resources and knowledge management, Peyke Nour, Vol. 6, No. 1, pp 2-13.[In persian].

[27] Svetlik \& Stavrou-Costea, E.(2007). Connecting human resources management and knowledge management, International Journal of Manpower, 28(3/4): 197-206. 